\title{
Effect of 24-week repeated short-time walking based training program on physical fitness of black Cameroonian obese women
}

\author{
Wiliam R. Guessogo ${ }^{1,2, *}$, Abdou Temfemo ${ }^{2,3}$, Samuel H. Mandengue ${ }^{2,4}$, Peguy B. Assomo Ndemba ${ }^{2}$, Regine T. Messina Ondoua ${ }^{1}$, André \\ Hamadou', Laurent S. Etoundi-Ngoa ${ }^{5}$, Said Ahmaidi ${ }^{4}$ \\ 'National Institute of Youth and Sports, Yaounde, Cameroon \\ 2Exercise and Sport Physiology Unit, Faculty of Sciences, University of Douala, Douala, Cameroon \\ ${ }^{3}$ Department of Biological Sciences, Faculty of Medicine and Pharmaceutical Sciences, University of Douala, Douala, Cameroon \\ 'Laboratoire EA3300 - APERE: Adaptations Physiologiques à l'Exercice et Réadaptations à l'Effort, Faculté des Sciences du Sport, Université de Picardie Jules Verne, \\ Amiens, Cedex, France \\ ${ }^{5}$ Department of Biological Sciences, ENS Yaounde, Yaounde, Cameroon
}

This study aimed to examine the effects of a training program based on repetition of short-time walk sequences on cardiorespiratory response, physical performance and metabolic parameters in black Cameroonian obese women. One hundred thirty-nine obese women (body mass in$\operatorname{dex}[\mathrm{BMI}]>30 \mathrm{~kg} / \mathrm{m}^{2}$ ) were divided into three groups: premenopausal (Pre-M; $39.7 \pm 7.9$ yr; $n=48$ ), postmenopausal (Post-M; $55.0 \pm 2.5$ yr; $\mathrm{n}=61$ ) and control group (CONT; $48.7 \pm 9.4 \mathrm{yr} ; \mathrm{n}=30$ ). Only Pre-M and Post-M completed 24-week repeated short-time walking program. Anthropometric, cardiorespiratory, metabolic parameters, and the 6-min walk distance (6MWD) were measured at baseline (S1), 12 weeks follow-up (S2), and 2 days after the last session (S3). Significant changes were observed in weight, BMI, fatty mass and 6MWD in Pre-M and Post-M after 24 weeks. The waist and hip circumferences, percentages of water, muscle mass and bone mass changed in Post-M. Total cholesterol, triglycerides, low density lipoprotein and forced expiratory volumes in 1 and 6 sec showed significant improvements in Pre-M and Post-M. High density lipoprotein increased only in Post-M $(0.5 \pm 0.2 \mathrm{~g} / \mathrm{L}$ vs $0.7 \pm 0.1 \mathrm{~g} / \mathrm{L}, P=0.041$ ). In conclusion, this training modality could constitute an option for obese women rehabilitation.

Keywords: Repeated short-time walking, Walk test, Physical fitness, Black obese women

\section{INTRODUCTION}

Obesity is a major public health problem in the world. The number of obese peoples increases significantly, and developing countries are highly concerned (World Health Organization, 2010). Regular practice of aerobic physical activities is an important mean to prevent chronic diseases (Ho et al., 2012). The increase of exercise capacities and physical fitness result in several health benefits (Vanhees et al., 2005). The Australian National Physical Activity Guidelines for Adults recommend more than 30 min of daily physical activity (National Health and Medical Re- search, 1999).

A variety of exercise training are used to reduce obesity. The effects of low intensity aerobic exercises (Dumortier et al., 2003; Johnson et al., 2007), or anaerobic high intensity exercises (Sigal et al., 2007), have been assessed in obese individuals. Ho et al. (2012) reported that the benefits in obese patients in weight loss, fat loss and cardiorespiratory fitness improvement were greater when aerobic and anaerobic exercises were combined, compared to single aerobic or anaerobic. Many studies using discontinuous and/or continuous exercises showed comparable effects in taking care of obese individuals (Coquart et al., 2012; Dansou et al.,
${ }^{\star}$ Corresponding author: Wiliam R. Guessogo (D) http://orcid.org/0000-0002-1015-3583 National Institute of Youth and Sports, PO Box 1016 INJS Yaounde, Cameroon Tel: +237-677-815-321, Fax: +237-222-227-298, E-mail: guessowiliam@yahoo.fr Received: November 16, 2015 / Accepted: April 5, 2016
This is an Open Access article distributed under the terms of the Creative Commons Attribution Non-Commercial License (http://creativecommons.org/licenses/by-nc/4.0/) which permits unrestricted non-commercial use, distribution, and reproduction in any medium, provided the original work is properly cited. 
2000). Nevertheless, Coquart et al. (2012) showed that obese patients preferred similarly the constant velocity walk and the intermittent walk because of the break with the monotony of constant velocity (continuous) exercises frequently proposed during training sessions. Other training programs for obese individuals, are based on intermittent and/or repeated short bouts exercises. In an 18-month longitudinal study, Jakicic et al. (1999) compared effects of intermittent with traditional continuous exercise on weight loss, adherence and fitness in obese subjects. They found that subjects of short bouts group did not experience improvement in long-term weight loss, exercise participation, or cardiorespiratory fitness, compared to long bout exercises. In another hand, numerous studies compared the effects of long duration exercises to repeated short duration bouts (Guidry et al., 2006; Manthou et al., 2015; Murphy and Hardman, 1998; Osei-Tutu and Campagna, 2005; Serwe et al., 2011).

In our knowledge, studies using repeated exercises as well as their longitudinal effects are scarce in the literature. The present study aimed to evaluate the effects of a training program based on the repetition of short-time walk sequences as the 6-min walk test (6MWT) on cardiorespiratory responses, physical performance and metabolic parameters in obese black Cameroonian women.

\section{MATERIALS AND METHODS}

\section{Participants}

One hundred seventy-four sedentary obese women (body mass index $[\mathrm{BMI}]>30 \mathrm{~kg} / \mathrm{m}^{2}$ ) accepted voluntarily to participate in the study. All are adherents of a rehabilitation center for no more than one month ago with no physical activity history. They expressed their agreement by signing consent prior to the experiment and the experimental protocol was in accordance with the ethical principles the Declaration of Helsinki, 1975. This study was approved by the National Ethics Committee for the Research in Human Health of Ministry of Public Health of Cameroon. Smokers, peoples living with diabetes, those under phospholipid control medications, and those suffering from any disease which could limit walking capacity were excluded; and finally 139 were included. Because of the potential effect of hormones on the physical capacity, participants were divided into three groups: 48 premenopausal (Pre-M) women, 61 postmenopausal (Post-M) women and 30 control (CONT) women.

\section{Protocol design}

The experiment was conducted in 3 sessions (S1, S2, and S3) with 12 weeks between 2 sessions. During the first (S1) and the third (S3) sessions, each participant completed alone two walking tests separated at least by $48 \mathrm{hr}$ : the $2-\mathrm{km}$ walk test $(2 \mathrm{kmWT})$ before and the 6-min walk test (6MWT) after. In the second session (S2), only the 6MWT was completed by the participants. The $2 \mathrm{kmWT}$ was used for estimation of the maximal oxygen consumption $\left(\mathrm{VO}_{2 \max }\right)$ using the Urho Kaleva Kekkonen (UKK) method (UKK Institute, 2006). The 6MWT was used to evaluate the program and determine the intensity of the training exercise.

\section{Rehabilitation program}

The duration of the rehabilitation period was 24 weeks and 4 days per week, and concerned only the Pre-M and Post-M women. All participants were refrained to carry any other physical activities programs during the 24 weeks, apart from natural and common daily activities inherent to normal basic sedentary life. The participants were not requested to change their lifestyle or feeding habits over the program since forcing excessive diet to elderly women causes reduction in lean mass, which can cause protein loss, cardiac disorders, and severe risk in health (Beyul and Budagovsky, 1992). In another regard, in Cameroonian context, diet is a weekly turn over; and we did not modify the diet to effectively see the outcome of the program even in keeping the common and regular diet.

Each session of rehabilitation (1 hr $30 \mathrm{~min}$ ) consisted of 20-min warm up (slow to moderate walking, stretching, and respiratory gymnastics) and 60-min main exercise. The main exercise consisted in five repetitions of walking during 6 min (6MWT), with 6-min pause period between repetitions. The walking intensity was determined as a percentage of the distance walked during the previous session. For intervention weeks 1 to 12 , the intensity of exercise was $95-105 \%$ of the 6MWT distance measured in S1; for intervention weeks 12 to 24 , the intensity of exercise was 95 $105 \%$ of the 6MWT distance measured in S2. All recoveries were active made of slow walking, stretching and exercise relaxation with stereotyped gestures for participants.

\section{Tests}

Tests were conducted in a handball court, on an oval track (with 1 lap $=100 \mathrm{~m}$ ). During each test, labeled blocks (1-20) were used to determine the number of laps.

The $2 \mathrm{kmWT}$ consisted of walking briskly 2,000 m (20 laps) alone; and the time elapsed was registered. This test aimed to estimate the $\mathrm{VO}_{2 \max }\left(\mathrm{mL} \mathrm{O}_{2} / \mathrm{min} / \mathrm{kg}\right)$ at $\mathrm{S} 1$ and $\mathrm{S} 3$, and the evaluation of the training program effects. 
The 6MWT was performed according to the American Thoracic Society guidelines (ATS Committee on Proficiency Standards for Clinical Pulmonary Function Laboratories, 2002) in the same court, and the distance covered after 6-min walking (6MWD) was determined by an experimented technician. The technician approached the participant in the last seconds of walk to drop a block in the point reached the 6th min. The 6MWT was performed at S1, S2, and S3. During each test, participants were instructed to walk as far as possible, covering as much ground as possible and received standardized verbal encouragement.

\section{Metabolic parameters}

Total cholesterol (TC), high density lipoprotein cholesterol (HDL-C), and triglycerides (TG) were determined using a Cardiochek portable whole blood analyzer (Cardiochek PA, Polymer Technology Systems Inc., Indianapolis, IN, USA) at the beginning (S1) and at the end of the program (S3). This method using whole blood collected in from finger-tips was validated by Williams et al. (2011). Low density lipoprotein cholesterol (LDL-C) was calculated using the formula: LDL-C $=$ TC-HDL-C-TG/ 2.18. These measures were realized $48 \mathrm{hr}$ before the physical evaluation at the beginning of the program, and $48 \mathrm{hr}$ after the last test at the end of the program.

\section{Cardiorespiratory parameters}

Heart rate (HR) was continuously monitored from rest until the end of each test using a HR monitor Polar RS800CX (Electro Oy, Kempele, Finland) at S1, S2, and S3.

$\mathrm{VO}_{2 \max }$ was calculated at the end of the $2 \mathrm{kmWT}$ (S1 and S3) using the UKK method through the Polar Pro trainer 5 software (Electro Oy, Kempele, Finland). This method uses age, sex, weight, height, time elapsed, and HR at the end of the test for the estimation.

Respiratory volumes (forced expiratory volume $1 \mathrm{sec}\left[\mathrm{FEV}_{1}\right]$, forced expiratory volume $6 \mathrm{sec}\left[\mathrm{FEV}_{6}\right]$ and $\mathrm{FEV}_{1} / \mathrm{FEV}_{6}$ ratio) were determined at S1, S2, and S3 using an electronic peak flow meter (Piko 6, nSpire Health Inc., 1830 Lefthand Circle, Longmont, $\mathrm{CO}$, USA) and oxygen saturation $\left(\mathrm{SpO}_{2}\right)$ was determined at the same time with an electronic pulse oximeter (ChoiceMMed, OxyWatch C20, Beijing, China). These measures were done by the same investigator to guarantee an accurate assessment.

\section{Anthropometric parameters}

Weight, body water percentage $\left(\mathrm{H}_{2} \mathrm{O}\right)$, lean muscle mass $(\mathrm{MM})$, fat mass (FM), and bone mass (BM) were measured using a bio-im- pedance-meter scale TANITA BC 532 (Tokyo, Japan). The waist circumference $(\mathrm{WC})$ and the hip circumference $(\mathrm{HC})$ were measured using a nonextensible tape Butterfly. The BMI was calculated using the Quetelet formula BMI $\left(\mathrm{kg} / \mathrm{m}^{2}\right)=$ weight $(\mathrm{kg}) /$ height ${ }^{2}\left(\mathrm{~m}^{2}\right)$.

\section{Statistical analysis}

Data were analyzed with Statview 5.0 software (SAS Institute Inc., Cary, NC, USA). Data were expressed as mean \pm standard deviation. The comparison of mean values obtained in each parameter during the 3 sessions in each group was done using repeated measures analysis of variance. When necessary, a Fischer least significant difference post hoc test was performed to locate this difference. $t$-test for paired samples permitted to compare the mean values of parameters measured at the beginning and at the end of the program in each group. Comparison of the three groups after the program was done using unpaired $t$-test. The level of significance was set at $P<0.05$.

\section{RESULTS}

Anthropometric and performance parameters of the participants in this study are presented in Table 1. At baseline (S1), Pre-M, and Post-M differ significantly for age $(P=0.000)$, height $(P=0.026)$, and percentage of water $(P=0.022)$, but they did not differ for the other parameters measured. Pre-M was also different from CONT for age and height $(P<0.05)$. Six months $(24$ weeks) rehabilitation program induced a significant improvement of the walk area in six minutes. There was a significant increase of the 6MWD in Pre-M (698.6 $\pm 63.5 \mathrm{~m}$ vs $744.7 \pm 49.6 \mathrm{~m}, P<0.001)$ in Post-M $(705.1 \pm 29.8 \mathrm{~m}$ vs $730.3 \pm 38.6 \mathrm{~m}, P<0.01)$ and in CONT $(692.3 \pm 23.5 \mathrm{~m}$ vs $718.7 \pm 12.6 \mathrm{~m}, P<0.05)$. At the end of the program (S3), anthropometric characteristics of experimental groups were significantly different from $\mathrm{CONT}$ for $\mathrm{H}_{2} \mathrm{O}, \mathrm{FM}$, $\mathrm{BM}$, and 6MWD $(P<0.05)$.

The variations of anthropometric parameters during the program are also presented in Table 1. Significant changes were recorded in Pre-M and Post-M for weight, BMI and FM. We registered significant variations for $\mathrm{WC}, \mathrm{HC}, \mathrm{H}_{2} \mathrm{O}, \mathrm{MM}$, and $\mathrm{BM}$ only in Post-M. No significant anthropometric variation was noted in CONT. At the end of the program (S3), there was no difference between Pre-M and Post-M anthropometric and performance characteristics.

Table 2 shows the metabolic and cardiorespiratory parameters of the participants of the study. No statistically significant difference was observed in metabolic parameters and $\mathrm{VO}_{2 \text { peak }}$ between 
Table 1. Variation of anthropometrics parameters and performance of the participants during the program

\begin{tabular}{|c|c|c|c|c|c|c|c|c|c|}
\hline \multirow{2}{*}{ Parameter } & \multicolumn{3}{|c|}{$\operatorname{CONT}(n=30)$} & \multicolumn{3}{|c|}{ Pre-M (n=48) } & \multicolumn{3}{|c|}{ Post-M (n=61) } \\
\hline & S1 & S2 & S3 & S1 & S2 & S3 & S1 & S2 & S3 \\
\hline Age (yr) & & $48.7 \pm 9.4^{\alpha}$ & & & $39.7 \pm 7.9$ & & & $55.0 \pm 2.5^{\pi \pi m}$ & \\
\hline Height (cm) & & $164.5 \pm 5.8$ & & & $170.3 \pm 4.7^{\alpha, \pi}$ & & & $163.1 \pm 5.0$ & \\
\hline Weight (kg) & $91.2 \pm 13.3$ & $92.7 \pm 13.5$ & $92.3 \pm 13.4^{\alpha}$ & $103.6 \pm 22.1$ & $103.9 \pm 22.0$ & $102.8 \pm 21.9^{*}$ & $87.5 \pm 6.9$ & $87.2 \pm 7.0$ & $86.9 \pm 7.1^{* *}$ \\
\hline $\mathrm{BMI}\left(\mathrm{kg} / \mathrm{m}^{2}\right)$ & $33.9 \pm 6.3$ & $34.7 \pm 6.0$ & $34.6 \pm 5.9$ & $35.6 \pm 6.7$ & $35.5 \pm 6.7$ & $35.3 \pm 6.7^{*}$ & $33.0 \pm 2.7$ & $32.8 \pm 2.8$ & $32.7 \pm 2.8^{* *}$ \\
\hline$W C(\mathrm{~cm})$ & $98.4 \pm 12.4$ & $97.4 \pm 10.8$ & $98.2 \pm 10.3$ & $101.1 \pm 11.6$ & $101.4 \pm 11.3$ & $101.2 \pm 12.0$ & $94.4 \pm 10.2$ & $94.3 \pm 10.2$ & $94.2 \pm 10.3^{*}$ \\
\hline $\mathrm{HC}(\mathrm{cm})$ & $120.4 \pm 9.2$ & $119.8 \pm 6.8$ & $119.5 \pm 8.7$ & $123.4 \pm 8.9$ & $122.8 \pm 9.1$ & $123.7 \pm 3.3$ & $115.1 \pm 6.2$ & $115.1 \pm 6.2$ & $115.0 \pm 6.2^{*}$ \\
\hline WC/HC (cst) & $0.8 \pm 0.1$ & $0.8 \pm 0.1$ & $0.8 \pm 0.1$ & $0.8 \pm 0.04$ & $0.8 \pm 0.04$ & $0.8 \pm 0.03$ & $0.8 \pm 0.1$ & $0.8 \pm 0.1$ & $0.8 \pm 0.1$ \\
\hline $\mathrm{H}_{2} \mathrm{O}(\%)$ & $39.4 \pm 2.1$ & $39.6 \pm 2.4$ & $40.0 \pm 2.1^{\alpha \beta \beta}$ & $38.1 \pm 1.9^{\pi}$ & $38.1 \pm 1.9$ & $38.2 \pm 2.0$ & $40.9 \pm 1.6$ & $41.2 \pm 1.7$ & $41.5 \pm 1.7^{* * *}$ \\
\hline $\mathrm{MM}(\%)$ & $47.1 \pm 4.6$ & $48.4 \pm 4.2$ & $48.2 \pm 3.8$ & $49.9 \pm 5.3$ & $50.0 \pm 4.7$ & $50.2 \pm 4.9$ & $46.1 \pm 2.7$ & $46.6 \pm 2.7$ & $46.9 \pm 2.7^{* *}$ \\
\hline $\mathrm{FM}(\%)$ & $44.8 \pm 3.8$ & $45.2 \pm 3.5$ & $44.4 \pm 3.7^{\alpha \beta \beta}$ & $47.2 \pm 3.4$ & $46.7 \pm 3.4$ & $46.4 \pm 3.5^{* *}$ & $42.9 \pm 2.9$ & $42.2 \pm 2.7$ & $41.6 \pm 2.8^{* * *}$ \\
\hline $\mathrm{BM}(\%)$ & $2.5 \pm 0.2$ & $2.6 \pm 0.2$ & $2.6 \pm 0.2^{\alpha, \beta}$ & $2.7 \pm 0.3$ & $2.7 \pm 0.3$ & $2.7 \pm 0.3$ & $2.5 \pm 0.1$ & $2.5 \pm 0.2$ & $2.6 \pm 0.2^{* *}$ \\
\hline 6MWD (m) & $692.3 \pm 23.5$ & $701.2 \pm 18.1$ & $718.7 \pm 12.6^{* \alpha \alpha \beta}$ & $698.6 \pm 63.5$ & $721.0 \pm 53.6^{\mu .}$ & $744.7 \pm 49.6^{* * *}$ & $705.1 \pm 29.8$ & $721.1 \pm 35.2$ & $730.3 \pm 38.6 *$ \\
\hline
\end{tabular}

Values are presented as mean \pm standard deviation.

CONT, control; Pre-M, premenopausal; Post-M, postmenopausal; BMI, body mass index; WC, waist circumference; HC, hip circumference; MM, muscle mass; FM, fat mass; $\mathrm{BM}$, bone mass; 6MWD, six-min walk distance.

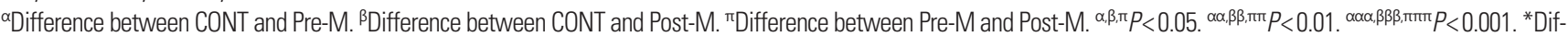

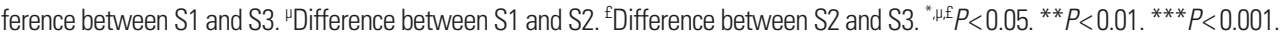

Table 2. Variation of metabolic and cardiorespiratory parameters in each group of participants during the program

\begin{tabular}{|c|c|c|c|c|c|c|}
\hline \multirow{2}{*}{ Parameter } & \multicolumn{2}{|c|}{ CONT $(n=30)$} & \multicolumn{2}{|c|}{ Pre-M (n=48) } & \multicolumn{2}{|c|}{ Post-M (n=61) } \\
\hline & S1 & S3 & S1 & S3 & S1 & S3 \\
\hline $\mathrm{VO}_{\text {2peak }}(\mathrm{mL} / \mathrm{kg} / \mathrm{min})$ & $23.0 \pm 5.5$ & $23.7 \pm 5.2$ & $23.8 \pm 7.0$ & $25.9 \pm 7.2$ & $24.9 \pm 4.7$ & $26.8 \pm 4.9$ \\
\hline $\mathrm{TC}(\mathrm{g} / \mathrm{L})$ & $2.1 \pm 0.4$ & $2.3 \pm 0.4^{\alpha}$ & $2.1 \pm 0.3$ & $1.8 \pm 0.3^{*}$ & $2.2 \pm 0.3$ & $1.9 \pm 0.3^{*}$ \\
\hline $\mathrm{TG}(\mathrm{g} / \mathrm{L})$ & $1.1 \pm 0.5$ & $1.2 \pm 0.3^{\alpha, \beta}$ & $1.3 \pm 0.3$ & $0.9 \pm 0.2^{* *}$ & $1.3 \pm 0.3$ & $1.0 \pm 0.2^{* *}$ \\
\hline LDL-C (g/L) & $1.3 \pm 0.1$ & $1.4 \pm 0.2^{\alpha, \beta}$ & $0.9 \pm 0.3$ & $0.7 \pm 0.2^{*}$ & $1.2 \pm 0.3$ & $0.8 \pm 0.2^{*}$ \\
\hline HDL-C (g/L) & $0.6 \pm 0.2$ & $0.6 \pm 01^{\alpha}$ & $0.6 \pm 0.2$ & $0.7 \pm 0.2$ & $0.5 \pm 0.2$ & $0.7 \pm 0.1^{*}$ \\
\hline $\mathrm{FEV}_{1}$ & $1.93 \pm 0.28$ & $1.95 \pm 0.16^{\alpha \alpha \beta}$ & $1.87 \pm 0.27$ & $2.32 \pm 0.14^{*}$ & $1.68 \pm 0.29$ & $2.12 \pm 0.17^{*}$ \\
\hline $\mathrm{FEV}_{6}$ & $2.24 \pm 0.33$ & $2.21 \pm 0.47$ & $2.33 \pm 0.45$ & $2.91 \pm 0.39^{*}$ & $2.41 \pm 0.50$ & $2.84 \pm 0.25^{*}$ \\
\hline $\mathrm{FEV}_{1} / \mathrm{FEV}_{6}$ & $0.86 \pm 0.04^{\beta}$ & $0.88 \pm 0.02^{\alpha, \beta}$ & $0.80 \pm 0.03^{\pi}$ & $0.81 \pm 0.04$ & $0.70 \pm 0.07$ & $0.74 \pm 0.06^{* \pi \pi}$ \\
\hline $\mathrm{SpO}_{2}$ & $96.7 \pm 1.2$ & $96.2 \pm 0.92^{\alpha \beta}$ & $98.7 \pm 0.57^{\pi}$ & $98.7 \pm 0.32$ & $97.0 \pm 0.54$ & $97.83 \pm 0.43^{\pi}$ \\
\hline
\end{tabular}

Values are presented as mean \pm standard deviation.

$\mathrm{VO}_{2 \text { peak, }}$ peak of oxygen consumption; HDL-C, high-density lipoprotein cholesterol; LDL-C, low-density lipoprotein cholesterol; TG, triglycerides; TC, total cholesterol; FEV ${ }_{1}$, forced expiratory volume $1 \mathrm{sec}$; $\mathrm{FEV}_{6}$, forced expiratory volume $6 \mathrm{sec} ; \mathrm{SpO}_{2}$, oxygen saturation.

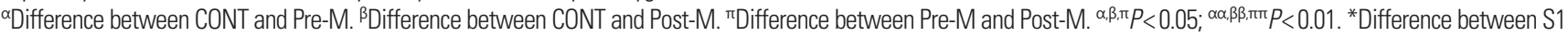
and S3. ${ }^{*} P<0.05 .{ }^{* *} P<0.01$.

groups at baseline. Significant differences were recorded in $\mathrm{FEV}_{1} /$ $\mathrm{FEV}_{6}$ ratio $(P=0.021)$ and $\mathrm{SpO}_{2}(P=0.012)$ between Pre-M and Post-M. At S3, differences were recorded between Pre-M and Post-M in $\mathrm{FEV}_{1} / \mathrm{FEV}_{6}$ ratio and $\mathrm{SpO}_{2}(P<0.05)$ (Table 2$)$. We also recorded a significant difference in $\mathrm{FEV}_{1} / \mathrm{FEV}_{6}$ ratio $(P<0.05)$ between Post-M and CONT women.

After the program, all metabolic and cardiorespiratory parameters changed significantly in Pre-M and Post-M, except $\mathrm{VO}_{\text {2peak }}$, $\mathrm{SpO}_{2}$, and HDL-C. No significant variation was noted in calculated $\mathrm{VO}_{2 \text { peak }}$ and $\mathrm{SpO}_{2}$ between $\mathrm{S} 1$ and $\mathrm{S} 3$. HDL-C significantly changed in Post-M $(P<0.05)$. CONT did not experience signifi- cant improvement of metabolic and cardiorespiratory parameters. After the program, Except $\mathrm{VO}_{2 \text { peak }}$ and $\mathrm{FEV}_{6}$, all the metabolic and cardiorespiratory parameters were different between experimental groups and CONT.

The comparisons of variations for different parameters are summarized in Table 3. All the metabolic parameters of experimental groups (Pre-M and Post-M) varied significantly from CONT but, the variation of the 6MWD was greater in Pre-M group $(P=$ $0.002)$. The program induces significant variations of weight $(P<0.001)$ and BMI $(P<0.01)$ in Pre-M and Post-M groups compared to CONT group. 
Table 3. Comparison of anthropometric and metabolic variations from S1 to S3

\begin{tabular}{|c|c|c|c|}
\hline Parameter & $\operatorname{CONT}(n=30)$ & Pre-M $(n=48)$ & Post-M (n=61) \\
\hline$\Delta$ Weight (kg) & $+0.36 \pm 0.49^{\alpha \alpha \alpha, \beta \beta \beta}$ & $-0.77 \pm 0.35^{* *}$ & $-0.67 \pm 0.55^{* *}$ \\
\hline$\Delta \mathrm{BMI}\left(\mathrm{kg} / \mathrm{m}^{2}\right)$ & $+0.13 \pm 0.20^{\alpha \alpha \beta \beta}$ & $-0.26 \pm 0.14^{* * *}$ & $-0.26 \pm 0.22^{* *}$ \\
\hline$\Delta \mathrm{WC}(\mathrm{cm})$ & $-0.21 \pm 0.70$ & $+0.07 \pm 0.85$ & $0.20 \pm 0.26^{*}, \pi$ \\
\hline$\Delta \mathrm{HC}(\mathrm{cm})$ & $+0.77 \pm 0.73^{\alpha, \beta \beta}$ & $+0.22 \pm 2.64$ & $-0.09 \pm 0.13^{*}, \pi$ \\
\hline$\Delta \mathrm{H} 2 \mathrm{O}(\%)$ & $-0.06 \pm 0.98$ & $+0.12 \pm 0.59$ & $+0.61 \pm 0.24^{* * * *}$ \\
\hline$\Delta \mathrm{MM}(\%)$ & $+0.23 \pm 0.86$ & $+0.26 \pm 0.60$ & $+0.74 \pm 0.60^{* * * *}$ \\
\hline$\Delta \mathrm{FM}(\%)$ & $+0.31 \pm 0.46^{\alpha \alpha . \beta \beta \beta}$ & $-0.87 \pm 0.53^{* * * *}$ & $-1.22 \pm 0.63^{* * *}, \pi$ \\
\hline$\Delta \mathrm{BM}(\%)$ & $+0.03 \pm 0.09$ & $+0.03 \pm 0.10$ & $+0.10 \pm 0.09^{* *}$ \\
\hline$\triangle 6 \mathrm{MWD}$ & $+11.89 \pm 9.35$ & $+46.11 \pm 36.20^{* * * *}$ & $+26.33 \pm 11.69^{* * \pi \pi} \pi$ \\
\hline$\Delta V O_{2 \text { peak }}(\mathrm{mL} / \mathrm{kg} / \mathrm{min})$ & $+0.2 \pm 0.4^{\alpha \alpha \alpha, \beta \beta \beta}$ & $+2.1 \pm 0.7$ & $+1.8 \pm 0.7$ \\
\hline$\Delta \mathrm{TC}(\mathrm{g} / \mathrm{L})$ & $+0.04 \pm 0.05^{\alpha, \beta}$ & $-0.37 \pm 0.42^{*}$ & $-0.34 \pm 0.25^{*}$ \\
\hline$\Delta \mathrm{TG}(\mathrm{g} / \mathrm{L})$ & $+0.03 \pm 0.04^{\alpha \alpha \alpha \beta \beta}$ & $-0.39 \pm 0.24^{* *}$ & $-0.35 \pm 0.2^{* * \pi} \pi$ \\
\hline$\Delta$ LDL-chol. (g/L) & $+0.04 \pm 0.06^{\alpha \beta}$ & $-0.29 \pm 0.38^{*}$ & $-0.31 \pm 0.29^{*}$ \\
\hline$\Delta \mathrm{HDL}$-chol. (g/L) & $-0.01 \pm 0.04^{\alpha \beta}$ & $+0.10 \pm 0.05$ & $+0.13 \pm 0.12^{* \pi} \pi$ \\
\hline
\end{tabular}

$\triangle$, variation; $\mathrm{BMI}$, body mass index; $\mathrm{WC}$, waist circumference; $\mathrm{HC}$, hip circumference; $\mathrm{MM}$, muscle mass; $\mathrm{FM}$, fat mass; $\mathrm{BM}$, bone mass; $\mathrm{VO}_{2 \text { peak, }}$ peak of oxygen consumption; HDL-C, high density lipoprotein cholesterol; LDL-C, low density lipoprotein cholesterol; TG, triglycerides; TC, total cholesterol; 6MWD, six-min walk distance.

${ }^{\alpha}$ Difference between CONT and Pre-M. ${ }^{\beta}$ Difference between CONT and Post-M. ${ }^{\pi}$ Difference between Pre-M and Post-M. ${ }^{\alpha . \beta \pi \pi} P<0.05 .{ }^{\alpha \alpha \beta \beta, \pi \pi} P<0.01$. ${ }^{\alpha \alpha \alpha . \beta \beta \beta, \pi \pi \pi} P<0.001$. ${ }^{*} P<0.05 .{ }^{*} P<0.01 .{ }^{* *} P<0.001$.

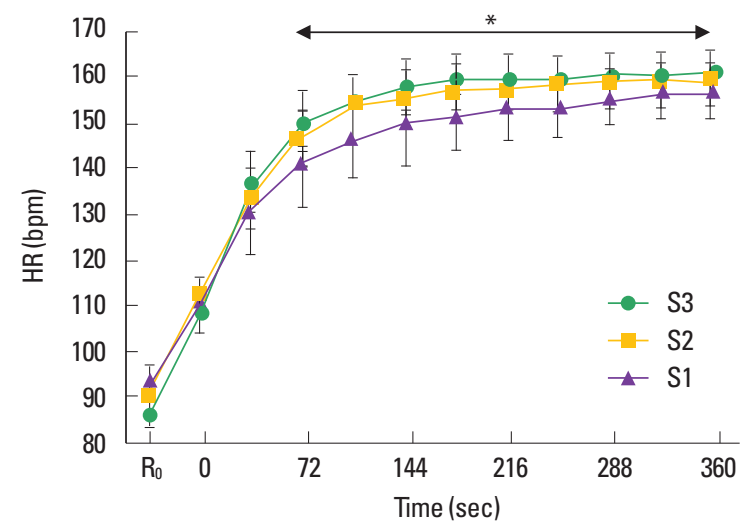

Fig. 1. Kinetics of heart rate during the 6-min walk test in the 3 sessions for the whole population $(S 1, S 2, S 3)$. HR, heart rate; $R_{0}$, resting HR. *Significant difference of $\mathrm{HR}$ between $\mathrm{S} 3$ and $\mathrm{S} 1$ at $P<0.05$.

We studied the HR variations during the 3 sessions in Pre-M and Post-M. Fig. 1 shows variations of HR during the 6MWT. There was a progressive increase between resting and warm up periods, and from the beginning of the walk until $1 / 3$ of the distance and/or the time. The HR kinetic during the last $2 / 3$ was almost a plateau. For the 3 sessions of walk in 6 min, the HR kinetics was similar with an important plateau during the 3 rd session than the 2nd, and significantly more important than the 1st session.

\section{DISCUSSION}

The aim of this study was to evaluate the effects of repetition of walking in 6-min sequences based training program, at intensity near that of the maximal of the 6MWT in obese women. The variables studied were anthropometric parameters, cardiorespiratory response, lung function indices, physical performance, and metabolic parameters with respect to menopausal status. The 24 weeks repeated short time walking program induced significant modifications in anthropometric parameters of Post-M. Furthermore, the program resulted in an improvement of physical fitness, cardiorespiratory function and lipid profile of Pre-M and Post-M; these improvements were more important in Pre-M. These results are consistent with those of Kravitz (2007) who found that moderated physical activities could improve the quality of life, and reduce risk factors to develop heart diseases, hypertension, many cancers and type 2 diabetes in patients of all ages.

After 24 weeks of training, we recorded significant beneficial decrease in anthropometric parameters in Post-M (Table 1). Our results are in accordance with the findings of Ho et al. (2012) who reported anthropometric and physiological changes after a long training period. In contrary, Grandjean et al. (1998) do not found any improvement in weight and body fat following a program of continuous exercises. Wiklund et al. (2014) do not also recorded body weight decrease after 6 weeks short-term moderate intensity aerobic exercise training in premenopausal women. 
In the present study, the distance covered in 6 min (6MWD) increased significantly over the program in the three groups. Ameliorations of 6.6\% (Pre-M, $P<0.001$ ), 3.6\% (Post-M, $P<0.01$ ), and $3.6 \%$ (CONT, $P<0.05$ ) were found in the $6 \mathrm{MWD}$ from $\mathrm{S} 1$ to $\mathrm{S} 3$. The 6MWD improvement observed in CONT can be explained by the learning effect of repeated sequences. Serwe et al. (2011) also noted in sedentary women, an increase of 6MWD after a training program comprising 3 sequences of $10 \mathrm{~min}$ of walk per day, 5 times per week, during 8 weeks. Thus, the intermittent walking program elicited an increase of physical fitness in obese women. Nevertheless, despite the nonsignificance improvement of $\mathrm{VO}_{2 \text { peak }}$ during the program $(+8.8 \%$ for Pre-M; $+7.6 \%$ for Post-M, and $+3.0 \%$ for CONT), this result was in accordance with that of Osei-Tutu and Campagna (2005) in sedentary subjects of both sexes $(6.7-7.2 \%)$. But, these changes are less than those obtained in the study of Trapp et al. (2008) who evaluated the effects of high intensity intermittent exercise (HIIE) training on fat loss and fasting insulin levels of young women. The HIIE resulted in a significant increase of $23.8 \%$ in post versus pretraining peak absolute oxygen uptake (Trapp et al., 2008). In their study, Schmidt et al. (2001) determined if 3 exercise sequences of 10 min per day $(3 \times 10)$ and, 2 sequences of 15 min per day $(2 \times 15)$ were also effective than a simple sequence of $30 \mathrm{~min}$ per day $(1 \times 30)$ in the amelioration of $\mathrm{VO}_{2 \max }$ and weight loss. The results of this study showed that exercises completed in several short duration sequences have the same effect as those completed in one continuous sequence, regarding aerobic fitness and weight loss in overweight girls. This improvement during the training program could be the result of an important increase of the cardiac flow and oxygen artero-veinous difference (Vanhees et al., 2005).

In order to determine whether accumulated short bouts of exercise can achieve the same cardiovascular benefits as a single long bout of exercise in sedentary male Japanese workers and to compare the program relative effects on oxidative stress, Eguchi et al. (2013) assigned randomly 23 subjects into 2 different exercise programs: a long-bout group $(30 \mathrm{~min} \times 1) 3$ days per week, and a short-bouts group $(10 \mathrm{~min} \times 3) 3$ days per week. Measured parameters were examined at baseline and after both 10 and 20 weeks. WC and $\mathrm{VO}_{2 \max }$ significantly improved in long-bout group after 20 weeks while a significant increase was noted after 10 weeks in short-bouts group.

The results of the present study showed a significant improvement $(P<0.05)$ in $\mathrm{FEV}_{1}$ and $\mathrm{FEV}_{6}$ during the program in Pre-M and Post-M women, and suggested our program can be used to train and ameliorate respiratory muscle strength. These findings agreed with those of Latorre-Roman et al. (2014) who analyzed the effects of a 12-week indoor intermittent training program on lung function in children with asthma. They showed significant improvement in $\mathrm{FEV}_{1}, \mathrm{FEV}_{6}$. Then, an indoor intermittent training program improved lung function and a regular physical exercise routine will greatly improve the quality of life. $\mathrm{But}, \mathrm{SpO}_{2}$ did not significantly change during the program, may be because of the normal status of this parameter at the beginning of the rehabilitation.

Our program induced many cardiorespiratory adaptations which allow an improvement of $\mathrm{VO}_{2 \max }$ and the blood volume. Furthermore, the training program ameliorated the capacity of the cardiovascular system to carry oxygen to tissue, by increasing the number of muscle mitochondrial enzymes and the total number of muscle capillaries (Henriksson, 1992). The oxidative enzyme increase occurs 6-8 weeks of training (Latorre-Roman et al., 2014), and we think our long duration training program to induce a significant improvement of the cardiorespiratory fitness of obese women.

The present study found a significant increase $(P<0.05)$ of HR from S1 to S3 (Fig. 1). This HR increase could be explained by the amelioration of the physical performance (6MWD) observed during the program. This result supposed an amelioration of the cardiac reserve from the beginning to the end of the program and confirmed the enhancement of the cardiorespiratory fitness of participants. Therefore, a training program with short time repeated walk seems to induce similar benefits to that obtained by Schmidt et al. (2001) with continuous and intermittent work sequences.

Regarding metabolic parameters, the results of the present study demonstrated an amelioration of the lipid status of obese women in experimental groups (Tables 2 and 3). Furthermore, these variations are significant in Pre-M and Post-M compared to CONT. This result suggests that 24-week short time walking program have beneficial effect in obese women. Previous research demonstrated that high-intensity intermittent exercise enhances capacity for fat oxidation and mitochondrial enzyme activity (Burgomaster et al., 2005; Talanian et al., 2007; Trapp et al., 2008). Physical activity induces an important production of catecholamine which permits fat absorption and these hormones enable the adiposity liberation of free fatty acids by stimulating the adenylyl cyclase enzyme, starting point of TG hydrolysis (Monod and Flandrois, 2003).

In fact, we noted in Pre-M and Post-M a significant decrease of TC and LDL-C $(P<0.01)$, and TG $(P<0.05)$. But, we observed a significant increase of HDL-C after 24 weeks training program 
$(P<0.05)$ only in Post-M (Table 2). A 24-week training program based on the repetition of short-time walk sequences induces better metabolic status in obese women. Its effects seem marked in Post-M as indicated in HDL-C concentration of Pre-M and Post-M. Yanagibori et al. (1993) examined the effects of 12-week exercise walking on serum lipids in pre- and postmenopausal women, to elucidate the influence of menopausal status on the training effects. They noted after 12 weeks a significant decrease of body fat percentage in both groups and BMI only in premenopausal group. They also obtained common significant changes of TC, TG, HDL-C, and LDL-C in both groups. These results are in accordance with those of Eguchi et al. (2013) who obtained a significant increase in HDL-C after 20 weeks in the short-bouts group. These authors suggested that accumulated short bouts of exercise are an effective option for incorporating exercise into one's lifestyle. A muscle metabolism orientated to lipid utilization than glycogen could justify these variations (Brooks and Mercier, 1994). The program developed cellular and hormonal adaptations, increased the concentration of the lipoprotein lipase enzyme for lipid oxidation (Hardman, 1999). Aerobic training improves FM utilization by increasing the action of lipid $\beta$-oxidation enzyme (Wilmore and Costill, 1998).

The improvement of the cardiorespiratory response observed during the present study trained an increase of muscle oxygen extraction in organism which implies the utilization of lipid molecules. This type of exercise as the high-intensity intermittent exercise may result in enhanced lipid utilization (Trapp et al., 2008). Numerous previous studies showed similar results. Durstine et al. (2002) obtained a blood lipid concentration improvement during a longitudinal program of 15-20 miles jogging or briskly walk per week. Ameliorations of cholesterol (13\%) and triacylglycerol $(37 \%)$ were recorded in sedentary obese men, from the beginning to the end of a high intensity circuit training of $30 \mathrm{~min} / \mathrm{session}$, for a total of 6-hr exertion (Miller et al., 2014). When comparing the physical training effects in blood lipids, Grandjean et al. (1998) obtained different results following a 6-min intermittent walking program. In fact, the blood concentration of lipids did not change with training. Furthermore, Woolf-May et al. (1998) did not experience any variation of HDL-C, LDL-C, and TC after 18-week walking program.

In conclusion, this study showed that 24-week repeated short time walking program improved anthropometric parameters, physical fitness, cardiorespiratory response and lipid profile in obese women. These changes tended to be amplified in Post-M than Pre-M women. Twenty-four-week repeated walking im- proved pulmonary function, but did not train any significant variation of $\mathrm{SpO}_{2}$ in obese women. Repeated short time walking program could be used as an option for the management of obesity. This training modality could be implemented in rehabilitation program as an alternative to high intensity interval training or moderate intensity continuous training.

One limitation of this study is lack of assessment of quantity of calories intake by participants during the program. It would have also been interesting to see variations in blood pressure as a factor associated to obesity.

\section{CONFLICT OF INTEREST}

No potential conflict of interest relevant to this article was reported.

\section{ACKNOWLEDGMENTS}

The authors thank all the women who participated in this study. They are members of the Women National Institute of Youth and Sports Fitness Club.

\section{REFERENCES}

ATS Committee on Proficiency Standards for Clinical Pulmonary Function Laboratories. ATS statement: guidelines for the six-minute walk test. Am J Respir Crit Care Med 2002;166:111-117.

Beyul E, Budagovsky V. Handbook of nutrition. Moscow Medicine 1992;464.

Brooks GA, Mercier J. Balance of carbohydrate and lipid utilization during exercise: the "crossover" concept. J Appl Physiol (1985) 1994; 76:2253-2261.

Burgomaster KA, Hughes SC, Heigenhauser GJ, Bradwell SN, Gibala MJ. Six sessions of sprint interval training increases muscle oxidative potential and cycle endurance capacity in humans. J Appl Physiol (1985) 2005;98:1985-1990.

Coquart J, Sioud R, Grosbois JM, Lemaire C, Tourny-Chollet C, Castres I, Lemaître F, Garcin M. Détermination de l'exercice le mieux ressenti par des patientes obèses: exercice continu vs exercice intermittent. Diabetes Metab 2012;38:33-34.

Dansou P, Tolly PL, Yèhouénou B, Tossou R, Hadonou ML. The effect of soccer training on the levels of atherosclerotic lipids in the blood of obese subjects. Sante 2000;10:393-397.

Dumortier M, Brandou F, Perez-Martin A, Fedou C, Mercier J, Brun JF. Low intensity endurance exercise targeted for lipid oxidation im- 
proves body composition and insulin sensitivity in patients with the metabolic syndrome. Diabetes Metab 2003;29:509-518.

Durstine JL, Grandjean PW, Cox CA, Thompson PD. Lipids, lipoproteins, and exercise. J Cardiopulm Rehabil 2002;22:385-398.

Eguchi M, Ohta M, Yamato H. The effects of single long and accumulated short bouts of exercise on cardiovascular risks in male Japanese workers: a randomized controlled study. Ind Health 2013;51:563-571.

Grandjean PW, Crouse SF, O'Brien BC, Rohack JJ, Brown JA. The effects of menopausal status and exercise training on serum lipids and the activities of intravascular enzymes related to lipid transport. Metabolism 1998;47:377-383.

Guidry MA, Blanchard BE, Thompson PD, Maresh CM, Seip RL, Taylor $\mathrm{AL}$, Pescatello LS. The influence of short and long duration on the blood pressure response to an acute bout of dynamic exercise. Am Heart J 2006;151:1322.e5-12.

Hardman AE. Physical activity, obesity and blood lipids. Int J Obes Relat Metab Disord 1999;23 Suppl 3:S64-71.

Henriksson J. Effects of physical training on the metabolism of skeletal muscle. Diabetes Care 1992;15:1701-1711.

Ho SS, Dhaliwal SS, Hills AP, Pal S. The effect of 12 weeks of aerobic, resistance or combination exercise training on cardiovascular risk factors in the overweight and obese in a randomized trial. BMC Public Health 2012;12:704

Jakicic JM, Winters C, Lang W, Wing RR. Effects of intermittent exercise and use of home exercise equipment on adherence, weight loss, and fitness in overweight women: a randomized trial. JAMA 1999;282: 1554-1560

Johnson JL, Slentz CA, Houmard JA, Samsa GP, Duscha BD, Aiken LB, McCartney JS, Tanner CJ, Kraus WE. Exercise training amount and intensity effects on metabolic syndrome (from Studies of a Targeted Risk Reduction Intervention through Defined Exercise). Am J Cardiol 2007;100:1759-1766.

Kravitz L. The 25 most significant health benefits of physical activity and exercise. IDEA Fit J 2007;4:54-63.

Latorre-Román PÁ, Navarro-Martínez AV, García-Pinillos F. The effectiveness of an indoor intermittent training program for improving lung function, physical capacity, body composition and quality of life in children with asthma. J Asthma 2014;51:544-551.

Manthou E, Gill JM, Malkova D. Effect of exercise programs with aerobic exercise sessions of similar intensity but different frequency and duration on health-related measures in overweight women. J Phys Act Health 2015;12:80-86.

Miller MB, Pearcey GE, Cahill F, McCarthy H, Stratton SB, Noftall JC, Buckle S, Basset FA, Sun G, Button DC. The effect of a short-term high-intensity circuit training program on work capacity, body com- position, and blood profiles in sedentary obese men: a pilot study. Biomed Res Int 2014;2014:191797.

Monod H, Flandrois R. Physiologie du sport: bases physiologiques des activités physiques et sportives. 5th ed. Paris: Masson; 2003.

Murphy MH, Hardman AE. Training effects of short and long bouts of brisk walking in sedentary women. Med Sci Sports Exerc 1998;30:152157.

National Health and Medical Research Council. National physical activity guidelines for Australians. Canberra: Australian Government Publishing Service; 1999.

Osei-Tutu KB, Campagna PD. The effects of short- vs. long-bout exercise on mood, $\mathrm{VO}_{2 \max }$, and percent body fat. Prev Med 2005;40:92-98.

Schmidt WD, Biwer CJ, Kalscheuer LK. Effects of long versus short bout exercise on fitness and weight loss in overweight females. J Am Coll Nutr 2001;20:494-501.

Serwe KM, Swartz AM, Hart TL, Strath SJ. Effectiveness of long and short bout walking on increasing physical activity in women. J Womens Health (Larchmt) 2011;20:247-253.

Sigal RJ, Kenny GP, Boulé NG, Wells GA, Prud'homme D, Fortier M, Reid RD, Tulloch H, Coyle D, Phillips P, Jennings A, Jaffey J. Effects of aerobic training, resistance training, or both on glycemic control in type 2 diabetes: a randomized trial. Ann Intern Med 2007;147:357-369.

Talanian JL, Galloway SD, Heigenhauser GJ, Bonen A, Spriet LL. Two weeks of high-intensity aerobic interval training increases the capacity for fat oxidation during exercise in women. J Appl Physiol (1985) 2007;102:1439-1447.

Trapp EG, Chisholm DJ, Freund J, Boutcher SH. The effects of high-intensity intermittent exercise training on fat loss and fasting insulin levels of young women. Int J Obes (Lond) 2008;32:684-691.

UKK Institute. UKK walk test: tester's guide. Tampere (FI): UKK Institute; 2006.

Vanhees L, Lefevre J, Philippaerts R, Martens M, Huygens W, Troosters T, Beunen G. How to assess physical activity? How to assess physical fitness? Eur J Cardiovasc Prev Rehabil 2005;12:102-114.

Wiklund P, Alen M, Munukka E, Cheng SM, Yu B, Pekkala S, Cheng S. Metabolic response to 6-week aerobic exercise training and dieting in previously sedentary overweight and obese pre-menopausal women: a randomized trial. J Sport Health Sci 2014;3:217-224.

Williams AD, Ahuja KD, Brickwood KJ, Fell J. Evaluation of the Cardiochek portable whole blood analyser for use in the fitness industry. J Exerc Physiol 2011;14:62-71.

Wilmore JH, Costill DL. Physiologie du sport et de l'exercice. Adaptation physiologique à l'exercice physique. Bruxelles: De Boeck Université; 1998.

Woolf-May K, Kearney EM, Jones DW, Davison RC, Coleman D, Bird SR. 
The effect of two different 18-week walking programmes on aerobic fitness, selected blood lipids and factor XIIa. J Sports Sci 1998;16:701710.

World Health Organization. Global recommendations on physical activity for health. Geneva: World Health Organization; 2010
Yanagibori R, Kawakubo K, Gunji A, Aoki K, Miyashita M. Effects of 12 wk-exercise walking on serum lipids, lipoproteins and apolipoproteins in middle aged women--does menopause status influence training effects? Nihon Koshu Eisei Zasshi 1993;40:459-467. 